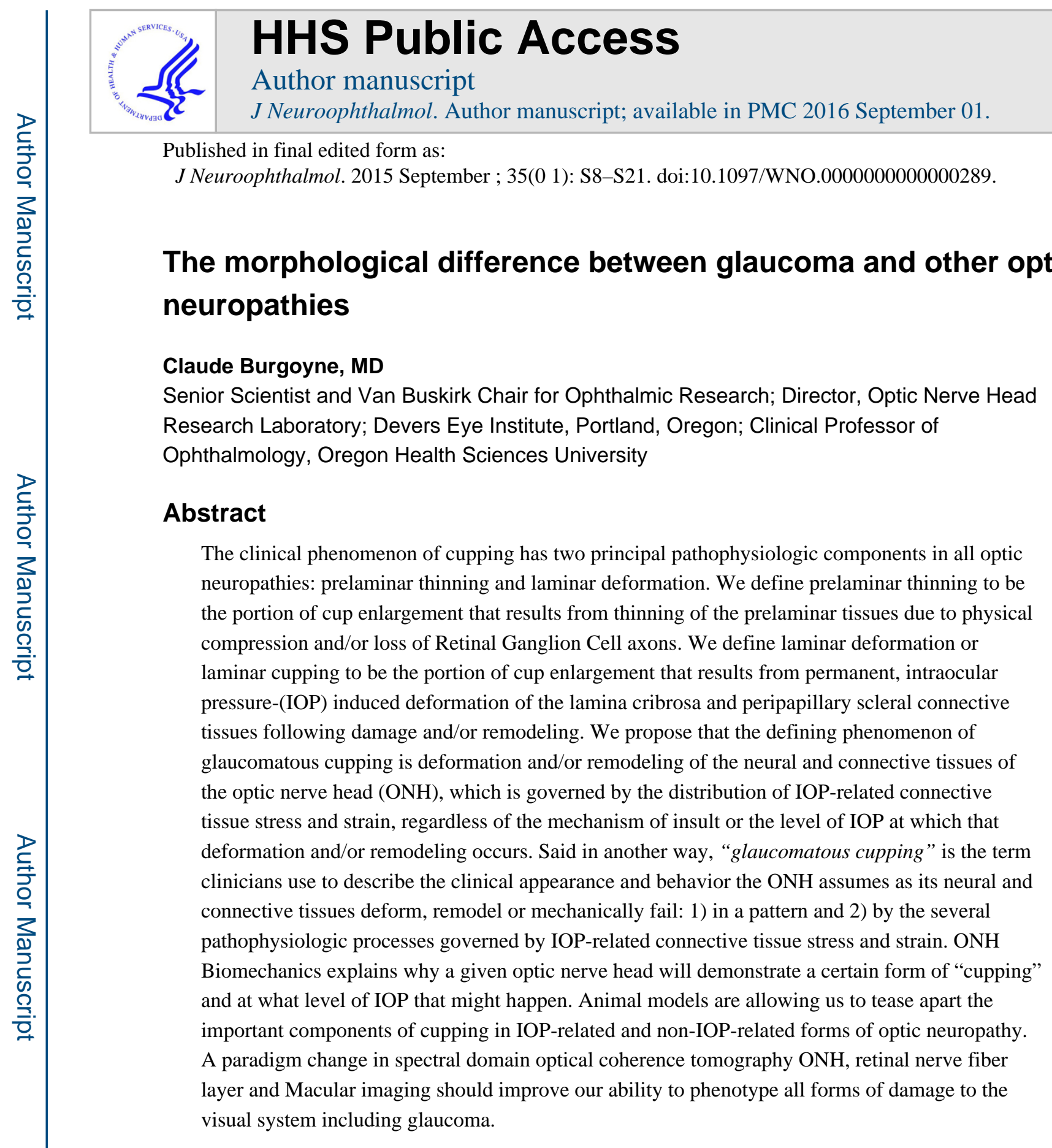

\title{
The Optic Nerve Head (ONH) in Glaucoma
}

Glaucoma is an optic neuropathy (1). While glaucomatous damage to the visual system likely includes important pathophysiologies within the retinal ganglion cell (RGC) body (24) photoreceptors, (5-11) peripheral RGC axon and its synapse $(12,13)$, lateral geniculate body (14-16) and visual cortex (16), strong evidence suggests that damage to the RGC

\footnotetext{
Author Conflicts of Interest: Dr. Burgoyne is NIH funded to study the effects of aging in the monkey experimental glaucoma model using 3D histomorphometric techniques. He is also NIH funded to use SDOCT imaging to translate techniques developed in monkeys to human patient care. In this regard, he is a consultant to Heidelberg Engineering from which he receives unrestricted research support and occasional travel funds but no honorarium or personal income. He has received no travel support or honorarium to attend this meeting.
} 
axons within the lamina cribrosa of the ONH (17-23) is a central pathophysiology. Studies in the monkey $(18,19,24-27)$, rat $(28,29)$, and mouse $(30,34)$, support the importance of the $\mathrm{ONH}$ by describing profound alterations and axonal transport disruption within the prelaminar, laminar and retrolaminar tissues of the $\mathrm{ONH}$ at the earliest detectable stage of experimental glaucoma (EG).

The ONH tissues make up a dynamic environment wherein 1.2 to 2.0 million RGC axons converge, turn, and exit the eye through the inner (Bruch's membrane opening (BMO)) and outer (scleral) portions of the neural canal (Fig 1). Within the scleral portion of the canal, the bundled axons pass through a 3-dimensional (3D) meshwork of astrocyte-covered, capillary containing, connective tissue beams known as the lamina cribrosa (Fig 1). Within the lamina, axonal nutrition is thought to depend upon the movement of oxygen and nutrients from the laminar capillaries through the laminar beam extracellular matrix, across the astrocyte basement membrane into the astrocyte, finally reaching the peripheral and central axons of each bundle, via cell processes (42).

\section{What really, is glaucomatous "cupping"?}

"Cupping" is a clinical term which is used to describe ONH structural change in all forms of optic neuropathy. However, "cupping" is also used as a synonym for the pathophysiology of glaucomatous damage to the $\mathrm{ONH}$. Because the clinical and pathophysiologic contexts for "cupping" are seldom clarified, there is a confusing literature regarding the presence, importance, and meaning of "cupping" in a variety of disorders. Cupping in glaucoma is highly variable $(43,44)$. We have previously proposed that only "laminar" or "deep" forms of "cupping" (those that include a connective tissue component) are pathognomonic for glaucoma $(27,37,45)$. We now further clarify that even a glaucomatous form of "cupping" is only one manifestation of the underlying pathophysiologic processes which contribute to the optic neuropathy of glaucoma. Cupping is a manifestation of the neuropathy of glaucoma, not the optic neuropathy itself. Damage to the RGC axon within the ONH is a second component of the optic neuropathy of glaucoma, but it also is not the optic neuropathy itself. While the pathophysiology of RGC axon damage is of fundamental importance in preserving vision, it may be only one component of, or secondary to, the larger pathophysiologic events that drive the neuropathy.

The clinical phenomenon of cupping has two principal pathophysiologic components in all optic neuropathies: prelaminar thinning and laminar deformation (Fig 2). We define prelaminar thinning to be the portion of cup enlargement that results from thinning of the prelaminar tissues due to physical compression and/or loss of RGC axons. We define laminar deformation, or laminar cupping, to be the portion of cup enlargement that results from permanent, intraocular pressure-(IOP) induced deformation (27) of the lamina cribrosa and peripapillary scleral connective tissues following damage and/or remodeling $(27,46-$ 48).

The clinical hallmarks of a glaucomatous optic neuropathy are "glaucomatous cupping" of the tissues of the $\mathrm{ONH}$ - a progressive posterior displacement of the surface of the $\mathrm{ONH}$, and progressive excavation of the prelaminar tissues beneath the anterior-most aspect of the 
scleral canal, the anterior scleral ring (Fig. 3, left) — and glaucomatous visual field loss, which most commonly starts as a nasal step and progresses through an arcuate scotoma to full hemifield loss. These clinical hallmarks distinguish a glaucomatous optic neuropathy from the many other optic neuropathies in which damage to the RGC axons, either at the nerve head or within the orbital optic nerve and chiasm, leads to RGC death. Although exceptions exist, ischemic, inflammatory, and compressive damage to the nerve head, orbital optic nerve, or optic chiasm usually results in pallor and atrophy of the nerve head but little or no excavation of the remaining rim tissue (Figure 3, right). In addition, in these entities the pattern of axon damage within the optic nerve, and as detected by visual field testing, is usually different from that of glaucomatous optic neuropathy.

While the $\mathrm{ONH}$ is the primary site of damage for a group of optic neuropathies, only a subset of these disorders assume the clinical appearance and behavior commonly associated with the term glaucomatous. What then constitutes a "glaucomatous" cupping? We propose that the defining phenomenon that underlies the glaucomatous optic neuropathies is deformation and/or remodeling of the neural and connective tissues of the $\mathrm{ONH}$, which is governed by the distribution of IOP-related connective tissue stress and strain, regardless of the mechanism of insult or the level of IOP at which that insult occurs. Said in another way, "glaucomatous cupping" is the term clinicians use to describe the clinical appearance and behavior the $\mathrm{ONH}$ assumes as its neural and connective tissues are deformed and/or remodeled: 1) in a pattern and 2) by the several pathophysiologic processes governed by IOP-related connective tissue stress and strain.

\section{Optic Nerve Head Biomechanics}

The biomechanical paradigm of glaucomatous ONH damage does not argue that the $\mathrm{ONH}$ is the earliest or only site of damage. ONH biomechanics provides a framework for explaining how IOP-related stress (force/cross-sectional area of the tissue experiencing that force) and strain (a measure of local deformation of a tissue induced by applied stress) within the loadbearing tissues of the $\mathrm{ONH}$ influence the physiology and pathophysiology of all three $\mathrm{ONH}$ tissue types at all levels of IOP. These include: 1 ) the connective tissues (load-bearing connective tissues of the peripapillary sclera, scleral canal wall, and lamina cribrosa), 2) the neural tissues (RGC axons), and 3) the cells which exist alone or in contact with both 1 and 2 (astrocytes, glial cells, endothelial cells, and pericytes and their basement membranes) (37, $45,46,50-54)$.

ONH biomechanics provides a logic by which non-IOP-related risk factors such as ischemia, inflammation, auto-immunity, astrocyte and glial molecular biology are influenced by or interact with the effects of IOP $(45,46)$. ONH biomechanics attempts to combine these "non-IOP-related" factors with laminar and peripapillary scleral connective tissue geometry and material properties (strength, stiffness, structural rigidity, compliance and nutrient diffusion properties) to explain the physiology of normal $\mathrm{ONH}$ aging, $\mathrm{ONH}$ susceptibility to IOP, and the clinical manifestation of all forms of optic neuropathy (Fig 4).

To understand when, why and how the lamina deforms at a given level of IOP in a given eye, and perhaps also to understand some portion of the contributing mechanisms of axonal 
insult in glaucoma, the biomechanical determinants of the translaminar pressure gradient or the transition from intraocular pressure to retrolaminar tissue pressure experienced by the $\mathrm{ONH}$ tissues are illustrated and explained in Figure 5. The importance of this gradient to axonal physiology is separately discussed below. The key messages of this and the following sections are five-fold. First, energy is required for axon transport and the translaminar pressure gradient may increase the energy requirements of the RGC axons within the lamina cribrosa. Second, IOP-related stresses and strains within the ONH connective tissues are complicated and do not necessarily lead to deformation of the lamina out of the plane of the sclera. Third, scleral canal expansion that tightens the lamina within the canal and lessens posterior laminar deformation still increases strain within the lamina. Fourth, posterior deformation of the lamina is likely not required for axon transport compromise. Fifth, IOP-related stress and strain within the ONH connective tissues may independently affect the delivery of nutrients to the RGC axons (and therefore affect axon transport) in the presence or absence of frank laminar deformation.

The difference between intraocular and orbital pressure establishes "engineering" or "mechanical" stresses (force/cross-sectional area of the tissue bearing the load) within the ONH neural and connective tissues, the magnitude of which is determined by the level of IOP and the 3-dimensional (3D) geometry or architecture of the tissues that carry them (45, 51, 56). These mechanical stresses are separate from physiologic stress which we define as physical and metabolic changes within a cell in response to alterations in its environment. The direct (outward) effect of IOP on the internal limiting membrane of the ONH prelaminar tissues is resisted by the pressure within the retrolaminar optic nerve tissues (retrolaminar tissue pressure) and the outward expansion of the scleral canal which pulls the lamina cribrosa "tight" within the canal, effectively increasing its resistance to outward deformation $(56,57)$.

The important concept for this discussion is that engineering models suggest that the stresses generated by the IOP/orbital pressure difference within the scleral connective tissues are far higher than the direct (outward) stresses on the neural and connective tissues of the lamina (Fig 2) $(54,56,58)$. How the ONH connective tissues respond to a given distribution of mechanical stress is determined by their material properties. A growing body of experimental $(57)$ and theoretical work $(52-53,58)$ supports the concept of a laminar-scleral dynamic in which the net compliance or rigidity of the sclera exerts a large influence over the magnitude of lamina cribrosa deformation at all levels of IOP. While a previous study of ONH surface deformation in dogs suggested substantial ONH surface movement with acute IOP elevation (59), recent studies in which laminar deformation was measured directly, suggest variable magnitudes of posterior laminar deformation follows acute IOP elevation in normal monkey $(18,60,61)$ and human eyes $(62)$.

How the axons respond to laminar deformation, cannot be separated from other axonal effects of the constituent neural and connective tissue stresses and strains. Said in another way, the components of IOP-related stress and strain that drive ONH connective tissue deformation may not be the components that influence axon transport. Glaucomatous damage to the RGC axons within the ONH may not simply occur at locations with the highest levels of IOP-related connective tissue strain or stress. Rather as neural and 
connective tissue stress and strain increase, axon physiology may become compromised at those locations where the translaminar tissue pressure gradient is steepest (Fig 5) and/or where the axon's energy supply is or otherwise becomes most vulnerable.

In these regards, it is important to clarify the separate concepts of the translaminar pressure difference (the difference between IOP and the retrolaminar tissue pressure) - which generates a net posterior (outward) force on the surface of the lamina, and the translaminar pressure gradient (schematically shown in green in Figure 2) which is the hydrostatic pressure gradient within the neural and connective tissues of the pre-laminar and laminar regions created by the translaminar pressure difference. Note that the in-plane hoop stress transferred to the lamina from the sclera is much larger than the stresses induced by the translaminar pressure difference (Fig 5). Cerebrospinal fluid (CSF) directly influences laminar position through its effect on the translaminar pressure difference. CSF may also effect scleral flange position within the region it projects to the sclera (Fig 2), but in most eyes, because the projection of the CSF space is minimal, this is likely not important.

IOP has a similar direct effect on laminar position, but has an additional (and potentially more important) effect through the peripapillary sclera. However, while the magnitude of the translaminar pressure difference may be small relative to the stresses within the connective tissues of the sclera and lamina, the axons separately experience it as the translaminar pressure gradient, the steepness of which is influenced by the thickness of the tissues over which it is experienced. In eyes with thin laminas or in which the lamina becomes thin through the course of the neuropathy $(55,53-66)$, the translaminar pressure gradient may serve as a primary barrier to axon transport and flow within this region and an important physiologic determinant for the $\mathrm{ONH}$ axons and cells.

To understand if and how the lamina cribrosa will deform and remodel at a given level of CSF-and IOP-induced load requires engineering finite element models that take into account the geometry of the $\mathrm{ONH}$ connective tissues and their constituent material properties. Taken together these components determine the net "structural stiffness" of the lamina cribrosa and peripapillary sclera. It is this net structural stiffness combined with the inherent propensity of the astrocytes to remodel the laminar extracellular matrix of the lamina at a given level of strain, that will determine whether a given eye demonstrates a shallow or deep form of cupping at a given translaminar pressure difference (Fig 6).

\section{“Cupping” in Four Monkey Optic Neuropathy Models}

We have characterized glaucomatous damage to the ONH tissues with the monkey model of chronic unilateral experimental IOP elevation using 3D histomorphometric and more recently spectral domain optical coherence tomography (SDOCT) imaging techniques (18, $19,25-27,47,60,67-69)$. Our studies together suggest that early "cupping" (0-30\% optic nerve axon loss) in the monkey $\mathrm{ONH}$ includes profound deformation and remodeling of the lamina cribrosa that includes "posterior" (outward migration) of both the anterior and posterior laminar insertions, laminar thickening that may also involve recruitment of the retrolaminar orbital optic nerve septa into more transversely oriented laminar beams. These 
laminar alterations occur in the setting of variable scleral canal expansion and myelin remodeling $(70,71)$ within the immediate retrolaminar orbital optic nerve (Figs 7, 8, 9).

As the neuropathy progresses, there is eventual thinning of the lamina, further expansion of the scleral canal, and splitting of the peripapillary sclera above the anterior most projection of the sub-arachnoid space (Fig 10). While our findings in advanced glaucoma support classic descriptions of advanced monkey and human disease, our findings of profound laminar remodeling early in the neuropathy are important because they depict "deep" glaucomatous cupping to be an active process of deformation and cellular remodeling rather than the passive response of deformation alone. Our findings in monkeys need to be confirmed in human disease. New SDOCTbased approaches to deep ONH imaging, (Figs 11 and 12 and covered briefly in the final section) should not only make this possible (targeting human ocular hypertensive patients) but will eventually allow for the characterization of the laminar component of cupping in all forms of clinical optic neuropathy.

Characteristics of three monkey experimental models of non-glaucomatous optic neuropathy have been reported (73-76). Not surprisingly, optic nerve head features of pallor without excavation were described in unilateral experimental anterior ischemic optic neuropathy (AION) $(74,75)$, and pallor accompanied by diffuse retinal nerve fiber layer thickness (RNFLT) loss without evidence of laminar deformation was demonstrated by SDOCT in a subset of animals that underwent chronic experimental CSF lowering (76). Our group found the lack of SDOCT-detected lamina cribrosa deformation in the setting of profound ONH rim and RNFLT loss in 5 animals followed longitudinally after unilateral surgical optic nerve transection (ONT) (73). These findings are in contrast to SDOCT detection of profound laminar deformation in the setting of early chronic IOP elevation (69).

The lack of laminar deformation in the AION, CSF-lowering and ONT models, while not surprising, is important because it distinguishes them from chronic unilateral IOP elevation. The finding of no laminar deformation in the setting of retinal nerve fiber layer (RNFL) loss in a subset of eyes following chronic CSF lowering is important for two reasons. First it suggests that the magnitude of translaminar pressure increase induced by CSF lowering from 12 to $4 \mathrm{mmHg}$ is not enough to overcome the scleral tensile forces (at normal levels of IOP) holding the lamina taut within the canal. Second, it suggests that while the translaminar pressure increase that resulted from primary CSF lowering did not induce laminar deformation, the translaminar pressure gradient increase likely contributed to axonal compromise at normal levels of IOP in a subset of eyes. This finding suggests the translaminar pressure gradient may be a risk factor for RGC axon loss at all levels of IOP. Finally, the presence of laminar deformation and remodeling in chronic IOP elevation is important because it confirms those phenomena to be defining features of the optic neuropathy of chronic IOP elevation that are detectable at its earliest clinically detectable stage.

The search for a model of low tension glaucoma is important to identify non-IOP-related insults that are capable of not just damaging axons in a glaucomatous pattern, but weakening the ONH connective tissues such that they deform and remodel at previously tolerated levels of "normal" IOP. We do not have an experimental model of glaucoma that does not require 
IOP elevation. Using SDOCT to detect early deformation of the lamina should be considered a target until proven otherwise. New SDOCT imaging paradigms for phenotyping the ONH/RNFLT/Macular tissues should enhance this kind of characterization (Figs 11, 12).

\section{OCT Paradigm Change in Phenotyping the ONH/RNFL/Macula of Monkeys and Humans}

Whether the desire is to detect laminar deformation in a human patient in which the role of IOP and its lowering is uncertain, or to detect laminar deformation in experimental models of normal pressure glaucoma, a new paradigm for SDOCT image acquisition and regionalization relative to the anatomic axis between the SDOCT detects fovea and the centroid of Bruch's membrane opening (77-81) should enhance our ability to phenotype all forms of damage to the visual system in diseases that are dear to both of our sub-specialties. A growing literature is using SDOCT and adaptive optics imaging to characterize the $\mathrm{ONH}$ cupping in all stages and manifestations of monkey and human glaucoma.

\section{Acknowledgments}

Portions of this syllabus have appeared in a series of previous publications $(27,37,45-47)$

\section{References}

1. Van Buskirk EM, Cioffi GA. Glaucomatous optic neuropathy. Am J Ophthalmol. 1992; 113:447452. [PubMed: 1558122]

2. Asai T, Katsumori N, Mizokami K. Retinal ganglion cell damage in human glaucoma. 2. Studies on damage pattern. Nihon Ganka Gakkai Zasshi. 1987; 91:1204-1213. [PubMed: 3448905]

3. Garcia-Valenzuela E, Shareef S, Walsh J, Sharma SC. Programmed cell death of retinal ganglion cells during experimental glaucoma. Exp Eye Res. 1995; 61:33-44. [PubMed: 7556468]

4. Quigley HA, Nickells RW, Kerrigan LA, Pease ME, Thibault DJ, Zack DJ. Retinal ganglion cell death in experimental glaucoma and after axotomy occurs by apoptosis. Invest Ophthalmol Vis Sci. 1995; 36:774-786. [PubMed: 7706025]

5. Janssen P, Naskar R, Moore S, Thanos S, Thiel HJ. Evidence for glaucoma-induced horizontal cell alterations in the human retina. Ger J Ophthalmol. 1996; 5:378-385. [PubMed: 9479522]

6. Quigley HA, McKinnon SJ, Zack DJ, Pease ME, Kerrigan-Baumrind LA, Kerrigan DF, Mitchell RS. Retrograde axonal transport of BDNF in retinal ganglion cells is blocked by acute IOP elevation in rats. Invest Ophthalmol Vis Sci. 2000; 41:3460-3466. [PubMed: 11006239]

7. Nork TM, Ver Hoeve JN, Poulsen GL, Nickells RW, Davis MD, Weber AJ, Vaegan, Sarks SH, Lemley HL, Millecchia LL. Swelling and loss of photoreceptors in chronic human and experimental glaucomas. Arch Ophthalmol. 2000; 118:235-245. [PubMed: 10676789]

8. Kendell KR, Quigley HA, Kerrigan LA, Pease ME, Quigley EN. Primary open-angle glaucoma is not associated with photoreceptor loss. Invest Ophthalmol Vis Sci. 1995; 36:200-205. [PubMed: 7822147]

9. Panda S, Jonas JB. Decreased photoreceptor count in human eyes with secondary angle-closure glaucoma. Invest Ophthalmol Vis Sci. 1992; 33:2532-2536. [PubMed: 1634350]

10. Weber AJ, Kaufman PL, Hubbard WC. Morphology of single ganglion cells in the glaucomatous primate retina. Invest Ophthalmol Vis Sci. 1998; 39:2304-2320. [PubMed: 9804139]

11. Wygnanski T, Desatnik H, Quigley HA, Glovinsky Y. Comparison of ganglion cell loss and cone loss in experimental glaucoma. Am J Ophthalmol. 1995; 120:184-189. [PubMed: 7639302] 
12. Crish SD, Sappington RM, Inman DM, Horner PJ, Calkins DJ. Distal axonopathy with structural persistence in glaucomatous neurodegeneration. Proc Natl Acad Sci U S A. 2010; 107:5196-5201. [PubMed: 20194762]

13. Crish SD, Dapper JD, MacNamee SE, Balaram P, Sidorova TN, Lambert WS, Calkins DJ. Failure of axonal transport induces a spatially coincident increase in astrocyte BDNF prior to synapse loss in a central target. Neuroscience. 2013; 229:55-70. [PubMed: 23159315]

14. Yucel YH, Zhang Q, Gupta N, Kaufman PL, Weinreb RN. Loss of neurons in magnocellular and parvocellular layers of the lateral geniculate nucleus in glaucoma. Arch Ophthalmol. 2000; 118:378-384. [PubMed: 10721961]

15. Yucel YH, Zhang Q, Weinreb RN, Kaufman PL, Gupta N. Atrophy of relay neurons in magno-and parvocellular layers in the lateral geniculate nucleus in experimental glaucoma. Invest Ophthalmol Vis Sci. 2001; 42:3216-3222. [PubMed: 11726625]

16. Yucel YH, Zhang Q, Weinreb RN, Kaufman PL, Gupta N. Effects of retinal ganglion cell loss on magno-, parvo-, koniocellular pathways in the lateral geniculate nucleus and visual cortex in glaucoma. Prog Retin Eye Res. 2003; 22:465-481. [PubMed: 12742392]

17. Vrabec F. Glaucomatous cupping of the human optic disk: a neuro-histologic study. Albrecht Von Graefes Arch Klin Exp Ophthalmol. 1976; 198:223-234. [PubMed: 1083166]

18. Bellezza AJ, Rintalan CJ, Thompson HW, Downs JC, Hart RT, Burgoyne CF. Deformation of the lamina cribrosa and anterior scleral canal wall in early experimental glaucoma. Invest Ophthalmol Vis Sci. 2003; 44:623-637. [PubMed: 12556392]

19. Burgoyne CF, Downs JC, Bellezza AJ, Hart RT. Three-dimensional reconstruction of normal and early glaucoma monkey optic nerve head connective tissues. Invest Ophthalmol Vis Sci. 2004; 45:4388-4399. [PubMed: 15557447]

20. Quigley HA, Guy J, Anderson DR. Blockade of rapid axonal transport. Effect of intraocular pressure elevation in primate optic nerve. Arch Ophthalmol. 1979; 97:525-531. [PubMed: 84662]

21. Quigley HA, Addicks EM, Green WR, Maumenee AE. Optic nerve damage in human glaucoma. II. The site of injury and susceptibility to damage. Arch Ophthalmol. 1981; 99:635-649. [PubMed: 6164357]

22. Minckler DS, Bunt AH, Johanson GW. Orthograde and retrograde axoplasmic transport during acute ocular hypertension in the monkey. Invest Ophthalmol Vis Sci. 1977; 16:426-441. [PubMed: 67096]

23. Gaasterland D, Tanishima T, Kuwabara T. Axoplasmic flow during chronic experimental glaucoma. 1 Light and electron microscopic studies of the monkey optic nervehead during development of glaucomatous cupping. Invest Ophthalmol Vis Sci. 1978; 17:838-846. [PubMed: 81192]

24. Downs JC, Suh JK, Thomas KA, Bellezza AJ, Hart RT, Burgoyne CF. Viscoelastic material properties of the peripapillary sclera in normal and early-glaucoma monkey eyes. Invest Ophthalmol Vis Sci. 2005; 46:540-546. [PubMed: 15671280]

25. Downs JC, Yang H, Girkin C, Sakata L, Bellezza A, Thompson H, Burgoyne CF. Threedimensional histomorphometry of the normal and early glaucomatous monkey optic nerve head: neural canal and subarachnoid space architecture. Invest Ophthalmol Vis Sci. 2007; 48:31953208. [PubMed: 17591889]

26. Yang H, Downs JC, Girkin C, Sakata L, Bellezza A, Thompson H, Burgoyne CF. 3-D histomorphometry of the normal and early glaucomatous monkey optic nerve head: lamina cribrosa and peripapillary scleral position and thickness. Invest Ophthalmol Vis Sci. 2007; 48:4597-4607. [PubMed: 17898283]

27. Yang H, Downs JC, Bellezza A, Thompson H, Burgoyne CF. 3-D histomorphometry of the normal and early glaucomatous monkey optic nerve head: prelaminar neural tissues and cupping. Invest Ophthalmol Vis Sci. 2007; 48:5068-5084. [PubMed: 17962459]

28. Johnson EC, Deppmeier LM, Wentzien SK, Hsu I, Morrison JC. Chronology of optic nerve head and retinal responses to elevated intraocular pressure. Invest Ophthalmol Vis Sci. 2000; 41:431442. [PubMed: 10670473] 
29. Johnson EC, Morrison JC, Farrell S, Deppmeier L, Moore CG, McGinty MR. The effect of chronically elevated intraocular pressure on the rat optic nerve head extracellular matrix. Exp Eye Res. 1996; 62:663-674. [PubMed: 8983948]

30. Danias J, Lee KC, Zamora MF, Chen B, Shen F, Filippopoulos T, Su Y, Goldblum D, Podos SM, Mittag T. Quantitative analysis of retinal ganglion cell (RGC) loss in aging DBA/2NNia glaucomatous mice: comparison with RGC loss in aging C57/BL6 mice. Invest Ophthalmol Vis Sci. 2003; 44:5151-5162. [PubMed: 14638711]

31. Filippopoulos T, Danias J, Chen B, Podos SM, Mittag TW. Topographic and morphologic analyses of retinal ganglion cell loss in old DBA/2NNia mice. Invest Ophthalmol Vis Sci. 2006; 47:19681974. [PubMed: 16639004]

32. Howell GR, Libby RT, Jakobs TC, Smith RS, Phalan FC, Barter JW, Barbay JM, Marchant JK, Mahesh N, Porciatti V, Whitmore AV, Masland RH, John SW. Axons of retinal ganglion cells are insulted in the optic nerve early in DBA/2J glaucoma. J Cell Biol. 2007; 179:1523-1537. [PubMed: 18158332]

33. Jakobs TC, Libby RT, Ben Y, John SW, Masland RH. Retinal ganglion cell degeneration is topological but not cell type specific in DBA/2J mice. J Cell Biol. 2005; 171:313-325. [PubMed: 16247030]

34. Schlamp CL, Li Y, Dietz JA, Janssen KT, Nickells RW. Progressive ganglion cell loss and optic nerve degeneration in DBA/2J mice is variable and asymmetric. BMC Neurosci. 2006; 7:66. [PubMed: 17018142]

35. Langham M. The temporal relation between intraocular pressure and loss of vision in chronic simple glaucoma. Glaucoma. 1980:427-435.

36. Anderson DR, Hoyt WF. Ultrastructure of intraorbital portion of human and monkey optic nerve. Arch Ophthalmol. 1969; 82:506-530. [PubMed: 4981187]

37. Burgoyne CF, Downs JC. Premise and prediction-how optic nerve head biomechanics underlies the susceptibility and clinical behavior of the aged optic nerve head. J Glaucoma. 2008; 17:318-328. [PubMed: 18552618]

38. Cioffi, GA.; Van Buskirk, EM. Vasculature of the anterior optic nerve and peripapillary choroid. In: Ritch, R.; Shields, MB.; Krupin, T., editors. The Glaucomas. St. Louis: Mosby; 1996. p. 177-197.

39. Quigley, HA. Overview and introduction to session on connective tissue of the optic nerve in glaucoma. In: Drance, SM.; Anderson, DR., editors. Optic Nerve in Glaucoma. Vol. Chapter 2. Amsterdam/New York: Kugler Publications; 1995. p. 15-36.

40. Quigley HA, Brown AE, Morrison JD, Drance SM. The size and shape of the optic disc in normal human eyes. Arch Ophthalmol. 1990; 108:51-57. [PubMed: 2297333]

41. Morrison JC, L'Hernault NL, Jerdan JA, Quigley HA. Ultrastructural location of extracellular matrix components in the optic nerve head. Arch Ophthalmol. 1989; 107:123-129. [PubMed: 2910271]

42. Anderson DR. Ultrastructure of human and monkey lamina cribrosa and optic nerve head. Arch Ophthalmol. 1969; 82:800-814. [PubMed: 4982225]

43. Nicolela MT, Drance SM. Various glaucomatous optic nerve appearances: clinical correlations. Ophthalmology. 1996; 103:640-649. [PubMed: 8618765]

44. Nicolela MT, McCormick TA, Drance SM, Ferrier SN, LeBlanc RP, Chauhan BC. Visual field and optic disc progression in patients with different types of optic disc damage: a longitudinal prospective study. Ophthalmology. 2003; 110:2178-2184. [PubMed: 14597527]

45. Burgoyne CF, Downs JC, Bellezza AJ, Suh JK, Hart RT. The optic nerve head as a biomechanical structure: a new paradigm for understanding the role of IOP-related stress and strain in the pathophysiology of glaucomatous optic nerve head damage. Prog Retin Eye Res. 2005; 24:39-73. [PubMed: 15555526]

46. Burgoyne CF. A biomechanical paradigm for axonal insult within the optic nerve head in aging and glaucoma. Exp Eye Res. 2011; 93:120-132. [PubMed: 20849846]

47. Yang H, Williams G, Downs JC, Sigal IA, Roberts MD, Thompson H, Burgoyne CF. Posterior (outward) migration of the lamina cribrosa and early cupping in monkey experimental glaucoma. Invest Ophthalmol Vis Sci. 2011; 52:7109-7121. [PubMed: 21715355] 
48. Roberts MD, Grau V, Grimm J, Reynaud J, Bellezza AJ, Burgoyne CF, Downs JC. Remodeling of the connective tissue microarchitecture of the lamina cribrosa in early experimental glaucoma. Invest Ophthalmol Vis Sci. 2009; 50:681-690. [PubMed: 18806292]

49. Quigley H, Anderson DR. Cupping of the optic disc in ischemic optic neuropathy. Trans Sect Ophthalmol Am Acad Ophthalmol Otolaryngol. 1977; 83:755-762.

50. Burgoyne CF, Morrison JC. The anatomy and pathophysiology of the optic nerve head in glaucoma. J Glaucoma. 2001; 10:S16-18. [PubMed: 11890263]

51. Sigal IA, Ethier CR. Biomechanics of the optic nerve head. Exp Eye Res. 2009; 88:799-807. [PubMed: 19217902]

52. Sigal IA, Flanagan JG, Tertinegg I, Ethier CR. Modeling individual-specific human optic nerve head biomechanics. Part II: influence of material properties. Biomech Model Mechanobiol. 2009; 8:99-109. [PubMed: 18301933]

53. Sigal IA, Flanagan JG, Tertinegg I, Ethier CR. Modeling individual-specific human optic nerve head biomechanics. Part I: IOP-induced deformations and influence of geometry. Biomech Model Mechanobiol. 2009; 8:85-98. [PubMed: 18309526]

54. Sigal IA. Interactions between geometry and mechanical properties on the optic nerve head. Invest Ophthalmol Vis Sci. 2009; 50:2785-2795. [PubMed: 19168906]

55. Morgan WH, Yu DY, Alder VA, Cringle SJ, Cooper RL, House PH, Constable IJ. The correlation between cerebrospinal fluid pressure and retrolaminar tissue pressure. Invest Ophthalmol Vis Sci. 1998; 39:1419-1428. [PubMed: 9660490]

56. Downs, JC.; Roberts, MD.; Burgoyne, CF. Mechanical Strain and Restructuring of the Optic Nerve Head. In: Shaarawy, T.; Sherwood, MB.; Hitchings, RA.; Crowston, JG., editors. Glaucoma. London: Saunders; 2009.

57. Bellezza AJ, Rintalan CJ, Thompson HW, Downs JC, Hart RT, Burgoyne CF. Anterior scleral canal geometry in pressurised (IOP 10) and non-pressurised (IOP 0) normal monkey eyes. Br J Ophthalmol. 2003; 87:1284-1290. [PubMed: 14507767]

58. Sigal IA, Flanagan JG, Ethier CR. Factors influencing optic nerve head biomechanics. Invest Ophthalmol Vis Sci. 2005; 46:4189-4199. [PubMed: 16249498]

59. Morgan WH, Chauhan BC, Yu DY, Cringle SJ, Alder VA, House PH. Optic Disc Movement with Variations in Intraocular and Cerebrospinal Fluid Pressure. Invest Ophthalmol Vis Sci. 2002; 43:3236-3242. [PubMed: 12356830]

60. Yang H, Downs JC, Sigal IA, Roberts MD, Thompson H, Burgoyne CF. Deformation of the normal monkey optic nerve head connective tissue after acute IOP elevation within 3-D histomorphometric reconstructions. Invest Ophthalmol Vis Sci. 2009; 50:5785-5799. [PubMed: 19628739]

61. Qin L, Yang H, Williams G, Gardiner S, Downs JC, Fortune B, Burgoyne CF. IOVS. 2012; 53:ARVO E-Abstract 2824.

62. Agoumi Y, Sharpe GP, Hutchison DM, Nicolela MT, Artes PH, Chauhan BC. Laminar and prelaminar tissue displacement during intraocular pressure elevation in glaucoma patients and healthy controls. Ophthalmology. 2011; 118:52-59. [PubMed: 20656352]

63. Morgan WH, Yu DY, Balaratnasingam C. The role of cerebrospinal fluid pressure in glaucoma pathophysiology: the dark side of the optic disc. J Glaucoma. 2008; 17:408-413. [PubMed: 18703953]

64. Jonas JB. Trans-lamina cribrosa pressure difference. Arch Ophthalmol. 2007; 125:431. author reply 431. [PubMed: 17353426]

65. Jonas JB, Berenshtein E, Holbach L. Lamina cribrosa thickness and spatial relationships between intraocular space and cerebrospinal fluid space in highly myopic eyes. Invest Ophthalmol Vis Sci. 2004; 45:2660-2665. [PubMed: 15277489]

66. Jonas JB, Berenshtein E, Holbach L. Anatomic relationship between lamina cribrosa, intraocular space, and cerebrospinal fluid space. Invest Ophthalmol Vis Sci. 2003; 44:5189-5195. [PubMed: 14638716]

67. Yang H, He L, Gardiner SK, Reynaud J, Williams G, Hardin C, Strouthidis NG, Downs JC, Fortune B, Burgoyne CF. Age-related differences in longitudinal structural change by spectral- 
domain optical coherence tomography in early experimental glaucoma. Invest Ophthalmol Vis Sci. 2014; 55:6409-6420. [PubMed: 25190652]

68. Yang H, Downs JC, Burgoyne CF. Physiologic intereye differences in monkey optic nerve head architecture and their relation to changes in early experimental glaucoma. Invest Ophthalmol Vis Sci. 2009; 50:224-234. [PubMed: 18775866]

69. He L, Yang H, Gardiner SK, Williams G, Hardin C, Strouthidis NG, Fortune B, Burgoyne CF. Longitudinal detection of optic nerve head changes by spectral domain optical coherence tomography in early experimental glaucoma. Invest Ophthalmol Vis Sci. 2014; 55:574-586. [PubMed: 24255047]

70. Nguyen JV, Soto I, Kim KY, Bushong EA, Oglesby E, Valiente-Soriano FJ, Yang Z, Davis CH, Bedont JL, Son JL, Wei JO, Buchman VL, Zack DJ, Vidal-Sanz M, Ellisman MH, MarshArmstrong N. Myelination transition zone astrocytes are constitutively phagocytic and have synuclein dependent reactivity in glaucoma. Proc Natl Acad Sci U S A. 2011

71. Davis CH, Kim KY, Bushong EA, Mills EA, Boassa D, Shih T, Kinebuchi M, Phan S, Zhou Y, Bihlmeyer NA, Nguyen JV, Jin Y, Ellisman MH, Marsh-Armstrong N. Transcellular degradation of axonal mitochondria. Proc Natl Acad Sci U S A. 2014; 111:9633-9638. [PubMed: 24979790]

72. Sigal IA, Flanagan JG, Tertinegg I, Ethier CR. 3D morphometry of the human optic nerve head. Exp Eye Res. 2010; 90:70-80. [PubMed: 19772858]

73. Ivers K, Ing E, Yang H, Gardiner SK, Reynaud J, Cull G, Wang L, Burgoyne CF. Lamina Cribrosa Position in the Monkey Optic Nerve Transection Model of a Non-Glaucomatous Optic Neuropathy. AGS Meeting Abstract. 2015 Accepted for presentation.

74. Chen CS, Johnson MA, Flower RA, Slater BJ, Miller NR, Bernstein SL. A primate model of nonarteritic anterior ischemic optic neuropathy. Invest Ophthalmol Vis Sci. 2008; 49:2985-2992. [PubMed: 18326695]

75. Miller NR, Johnson MA, Nolan T, Guo Y, Bernstein AM, Bernstein SL. Sustained Neuroprotection from a Single Intravitreal Injection of PGJ2 in a Non-Human Primate Model of Nonarteritic Anterior Ischemic Optic Neuropathy. Invest Ophthalmol Vis Sci. 2014 In press.

76. Yang D, Fu J, Hou R, Liu K, Jonas JB, Wang H, Chen W, Li Z, Sang J, Zhang Z, Liu S, Cao Y, Xie X, Ren R, Lu Q, Weinreb RN, Wang N. Optic neuropathy induced by experimentally reduced cerebrospinal fluid pressure in monkeys. Invest Ophthalmol Vis Sci. 2014; 55:3067-3073. [PubMed: 24736050]

77. Reis AS, Sharpe GP, Yang H, Nicolela MT, Burgoyne CF, Chauhan BC. Optic disc margin anatomy in patients with glaucoma and normal controls with spectral domain optical coherence tomography. Ophthalmology. 2012; 119:738-747. [PubMed: 22222150]

78. Reis AS, O'Leary N, Yang H, Sharpe GP, Nicolela MT, Burgoyne CF, Chauhan BC. Influence of clinically invisible, but optical coherence tomography detected, optic disc margin anatomy on neuroretinal rim evaluation. Invest Ophthalmol Vis Sci. 2012; 53:1852-1860. [PubMed: 22410561]

79. Chauhan BC, O'Leary N, Almobarak FA, Reis AS, Yang H, Sharpe GP, Hutchison DM, Nicolela MT, Burgoyne CF. Enhanced detection of open-angle glaucoma with an anamically accurate optical coherence tomography-derived neuroretinal rim parameter. Ophthalmology. 2013; 120:535-543. [PubMed: 23265804]

80. Chauhan BC, Burgoyne CF. From clinical examination of the optic disc to clinical assessment of the optic nerve head: a paradigm change. Am J Ophthalmol. 2013; 156:218-227. e212. [PubMed: 23768651]

81. He L, Ren R, Yang H, Hardin C, Reyes L, Reynaud J, Gardiner SK, Fortune B, Demirel S, Burgoyne CF. Anatomic vs. acquired image frame discordance in spectral domain optical coherence tomography minimum rim measurements. PLoS One. 2014; 9:e92225. [PubMed: 24643069]

82. Helb HM, Charbel Issa P, Fleckenstein M, Schmitz-Valckenberg S, Scholl HP, Meyer CH, Eter N, Holz FG. Clinical evaluation of simultaneous confocal scanning laser ophthalmoscopy imaging combined with high-resolution, spectral-domain optical coherence tomography. Acta Ophthalmol. 2010; 88:842-849. [PubMed: 19706019] 
83. Strouthidis NG, Fortune B, Yang H, Sigal IA, Burgoyne CF. Longitudinal change detected by spectral domain optical coherence tomography in the optic nerve head and peripapillary retina in experimental glaucoma. Invest Ophthalmol Vis Sci. 2011; 52:1206-1219. [PubMed: 21217108]

84. Ren R, Yang H, Gardiner SK, Fortune B, Hardin C, Demirel S, Burgoyne CF. Anterior lamina cribrosa surface depth, age, and visual field sensitivity in the Portland Progression Project. Invest Ophthalmol Vis Sci. 2014; 55:1531-1539. [PubMed: 24474264]

85. Gardiner SK, Ren R, Yang H, Fortune B, Burgoyne CF, Demirel S. A method to estimate the amount of neuroretinal rim tissue in glaucoma: comparison with current methods for measuring rim area. Am J Ophthalmol. 2014; 157:540-549. e541-542. [PubMed: 24239775]

86. Hosseini H, Nassiri N, Azarbod P, Giaconi J, Chou T, Caprioli J, Nouri-Mahdavi K. Measurement of the optic disc vertical tilt angle with spectral-domain optical coherence tomography and influencing factors. Am J Ophthalmol. 2013; 156:737-744. [PubMed: 23891337]

87. Lamparter J, Russell RA, Zhu H, Asaoka R, Yamashita T, Ho T, Garway-Heath DF. The influence of intersubject variability in ocular anatomical variables on the mapping of retinal locations to the retinal nerve fiber layer and optic nerve head. Invest Ophthalmol Vis Sci. 2013; 54:6074-6082. [PubMed: 23882689]

88. Strouthidis NG, Yang H, Reynaud JF, Grimm JL, Gardiner SK, Fortune B, Burgoyne CF. Comparison of clinical and spectral domain optical coherence tomography optic disc margin anatomy. Invest Ophthalmol Vis Sci. 2009; 50:4709-4718. [PubMed: 19443718] 

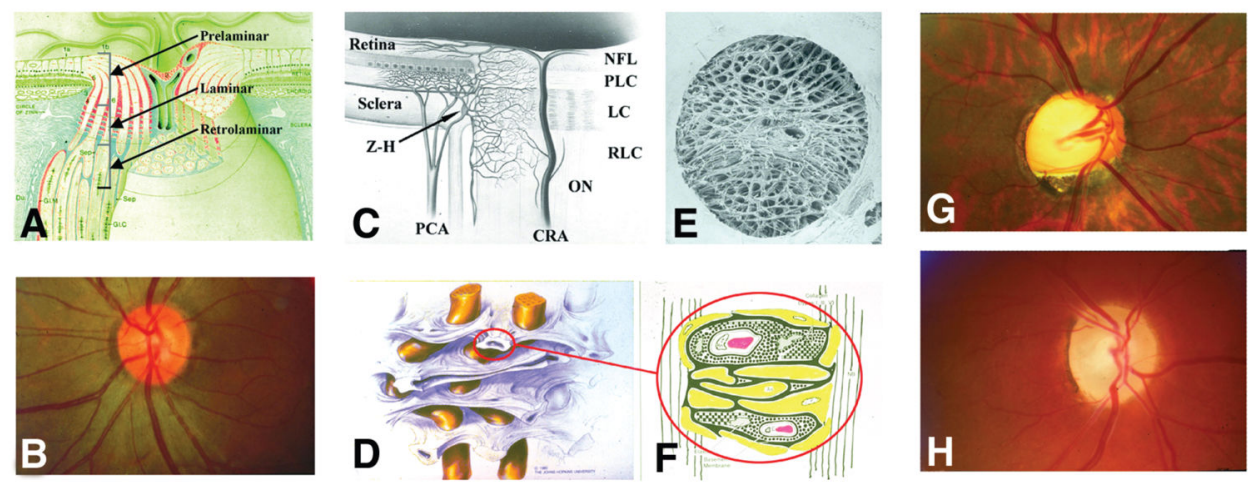

Figure 1. Glaucoma, cupping and axonal insult within the optic nerve head (ONH) The ONH is made up of prelaminar, laminar and retrolaminar regions (A). Within the clinically visible surface of the Normal ONH (referred to as the optic disc) (B), central retinal vessels enter the eye and RGC axons appear pink due to their capillaries (which are principally supplied by branches from the posterior ciliary arteries (PCA) in (C). The primary site of RGC axon insult in glaucoma is within the lamina cribrosa (schematically depicted with axon bundles in (D), isolated by trypsin digest in a scanning electron micrograph in (E) and drawn with stippled extracellular matrix (ECM), central capillary (red) and surrounding astrocytes (yellow with basement membranes in black) (F). Blood flow within the $\mathrm{ONH}$, while controlled by autoregulation, can be affected by non-IOPrelated effects such as systemic blood pressure fluctuation and vasospasm within the retrobulbar portion of the PCAs. Additional IOP-induced effects may include compression of PCA branches within the peripapillary sclera (due to scleral stress and strain) and compression of laminar beam capillaries reducing laminar capillary volume flow $(\mathrm{C}$ and $\mathrm{F})$ (35). There is no direct blood supply to the axons within the laminar region. Axonal nutrition within the lamina $(\mathrm{F})$ requires diffusion of nutrients from the laminar capillaries, across the endothelial and pericyte basement membranes, through the ECM of the laminar beam, across the basement membranes of the astrocytes, into the astrocytes, and across their processes to the adjacent axons (vertical lines). Chronic age-related changes in the endothelial cell and astrocyte basement membranes, as well as IOP-induced changes in the laminar ECM and astrocyte basement membranes may diminish nutrient diffusion to the axons in the presence of a stable level of laminar capillary volume flow. The clinical manifestation of IOP-induced ONH structural change is most commonly "deep cupping" (G) but in some eyes cupping can be shallower accompanied by pallor $(\mathrm{H})$. Z-H = circle of ZinnHaller; $\mathrm{PCA}=$ posterior ciliary arteries; $\mathrm{NFL}=$ nerve fiber layer; $\mathrm{PLC}=$ prelaminar region; $\mathrm{LC}=$ lamina cribrosa; $\mathrm{RLC}=$ retrolaminar region; $\mathrm{ON}=$ optic nerve; $\mathrm{CRA}=$ central retinal artery. [(A) Reprinted with permission from Arch Ophthalmol, copyright (C) 1969 American Medical Association. All rights reserved (36). (B) Reprinted with permission from Journal of glaucoma, copyright (C) 2008 Lippincott Williams \& Wilkins (37) (C) reprinted with permission from Dr. G. A. Cioffi (38) (D) Reprinted with permission from Optic Nerve in Glaucoma, Amsterdam: Kugler Publications (39). (E) Reprinted with permission from from Arch Ophthalmol, copyright (C) 1990 American Medical Association. All rights reserved (40). (F) Reprinted with permission from Arch Ophthalmol, copyright @ 1989 American 
Medical Association. All rights reserved (41). $(G, H)$ Reprinted with permission from Journal of glaucoma, copyright @ 2008 Lippincott Williams \& Wilkins (37)]. 


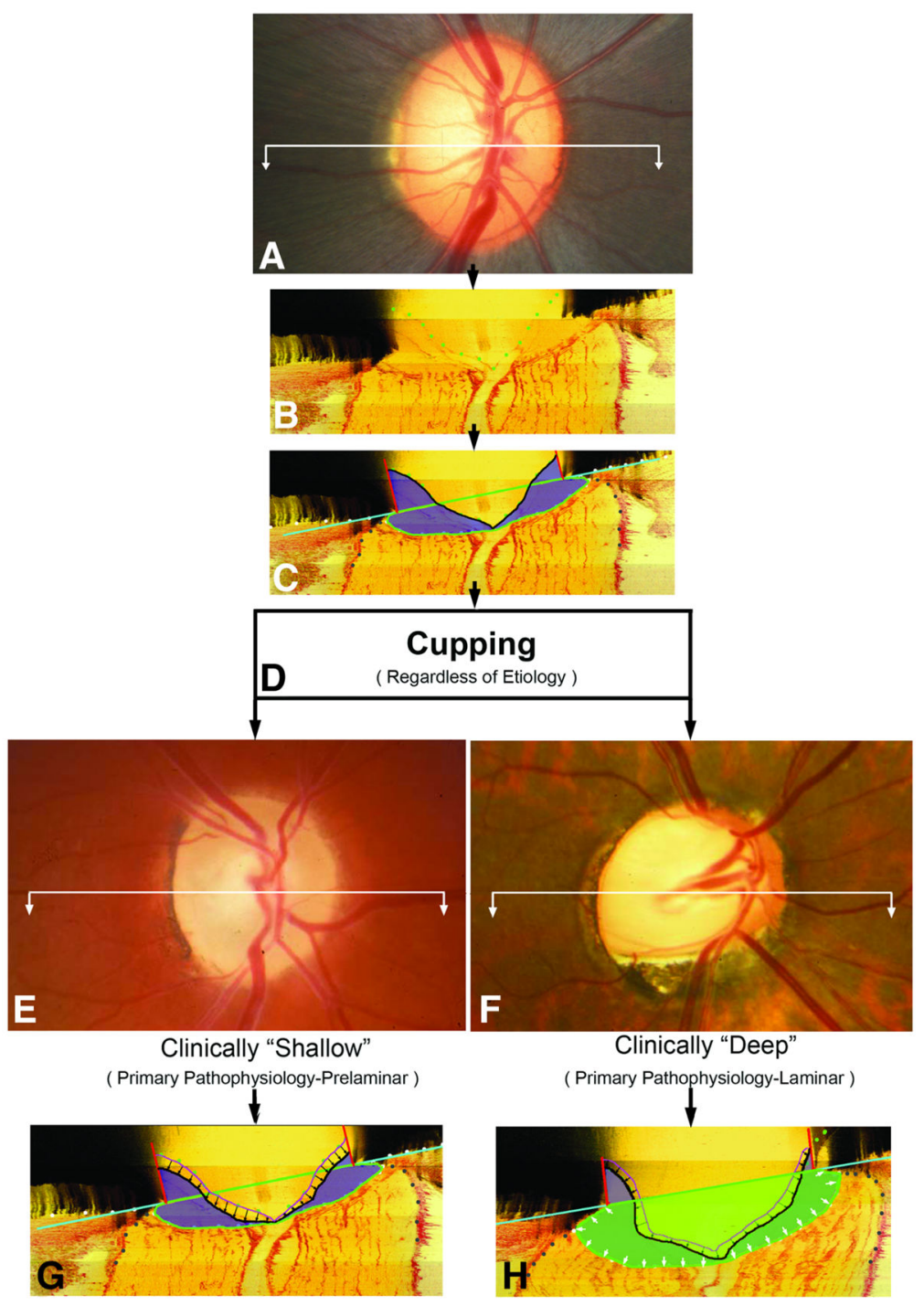

Figure 2. All Clinical Cupping, Regardless of Etiology, is a Manifestation of Underlying "Prelaminar" and "Laminar" Pathophysiologic Components

(A) Normal ONH. To understand the two pathophysiologic components of clinical cupping, start with (B) a representative digital central horizontal section image from a post-mortem $3 \mathrm{D}$ reconstruction of this same eye (white section line in $(\mathrm{A})$ ) - vitreous top, orbital optic nerve bottom, lamina cribrosa between the sclera and internal limiting membrane (ILM) delineated with green dots. (C) The same section is delineated into principle surfaces and volumes (Black - ILM; purple - prelaminar neural and vascular tissue; cyan blue line Bruch's Membrane Opening (BMO)-zero reference plane cut in section; green outline Post-BMO Total Prelaminar area or a measure of the space below BMO and the anterior laminar surface). (D) Regardless of the etiology, clinical cupping can be "shallow" (E) or "deep" (F) (these clinical photos are representative and are not of the eye in (A)). A prelaminar or "shallow" form of cupping (G, black arrows) is primarily due to loss (thinning) of prelaminar neural tissues without important laminar or ONH connective tissue involvement. Laminar or "deep" cupping (H, small white arrows depict expansion of the 
green shaded space) follows $\mathrm{ONH}$ connective tissue damage and deformation that manifests as expansion of the total area beneath $\mathrm{BMO}$, but above the lamina. Notice in $(\mathrm{H})$ that while a laminar component of cupping predominates (white arrows) there is a prelaminar component as well (black arrows). While prelaminar thinning is a manifestation of neural tissue damage alone, we propose that laminar deformation can only occur in the setting of ONH connective tissue deformation and remodeling. [Reprinted with permission from Investigative Ophthalmology \& Visual Science, copyright $\odot 2007$ Association for Research in Vision and Ophthalmology (27)]. ONH, optic nerve head; ILM, internal limiting membrane; BMO, Bruch membrane opening 

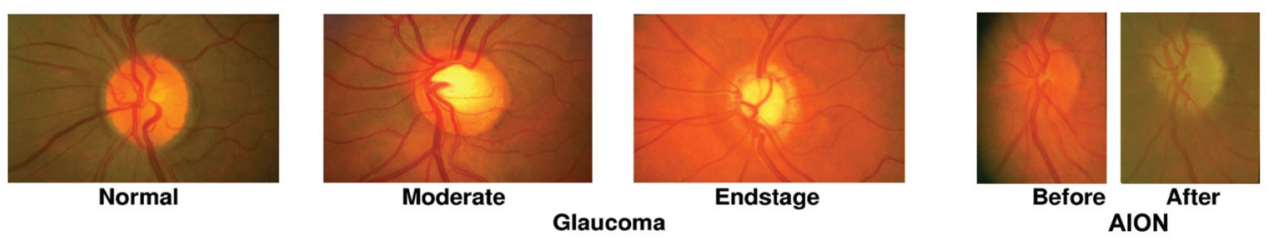

Figure 3. Progressive deformation and excavation of the tissues of the optic nerve head (ONH) beneath Bruch's Membrane Opening (BMO) and/or the anterior rim of the scleral canal is the clinical hallmark of a glaucomatous optic neuropathy (middle)

Axonal damage resulting from an episode of anterior ischemic optic neuropathy (AION), right, usually results only in $\mathrm{ONH}$ pallor. 


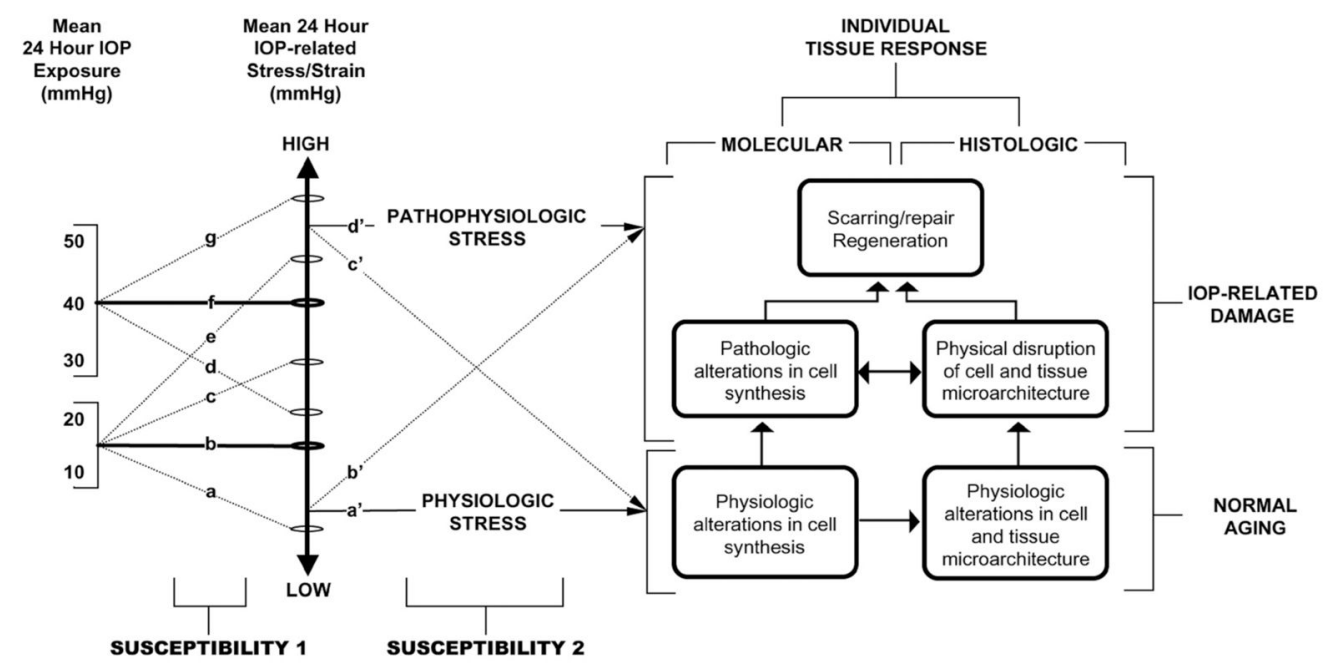

Figure 4. Whether, Over the Course of a Lifetime, an Eye Demonstrates the "Neuropathy of Aging" or the Neuropathy of Glaucoma Lies in ONH Susceptibility

For a given ONH, IOP generates low or high levels of stress ( $\mathrm{a}-\mathrm{g}$, vertically, above

"Susceptibility 1") depending upon the 3D architecture (geometry) of the ONH connective tissues (size and shape of the canal, thickness of the lamina and sclera)- (Susceptibility 1). Some ONHs will have relatively low stress at high IOP (d). Others will have high stress at low IOP (e). Whether a given level of IOP-related stress is physiologic or patho-physiologic depends upon the ONH's microenvironment (Susceptibility 2). Strong connective tissues, a robust blood supply and stable astrocytes and glia increase the chance of Normal ONH Aging (right - bottom). While the existence of a neuropathy of aging is controversial, the difference between "normal" age-related axon loss (if it is shown to exist) and the development of glaucomatous damage is a matter of ONH susceptibility. [Reprinted with permission from Journal of Glaucoma, copyright (C) 2008 Lippincott Williams \& Wilkins (37)]. IOP, intraocular pressure. 


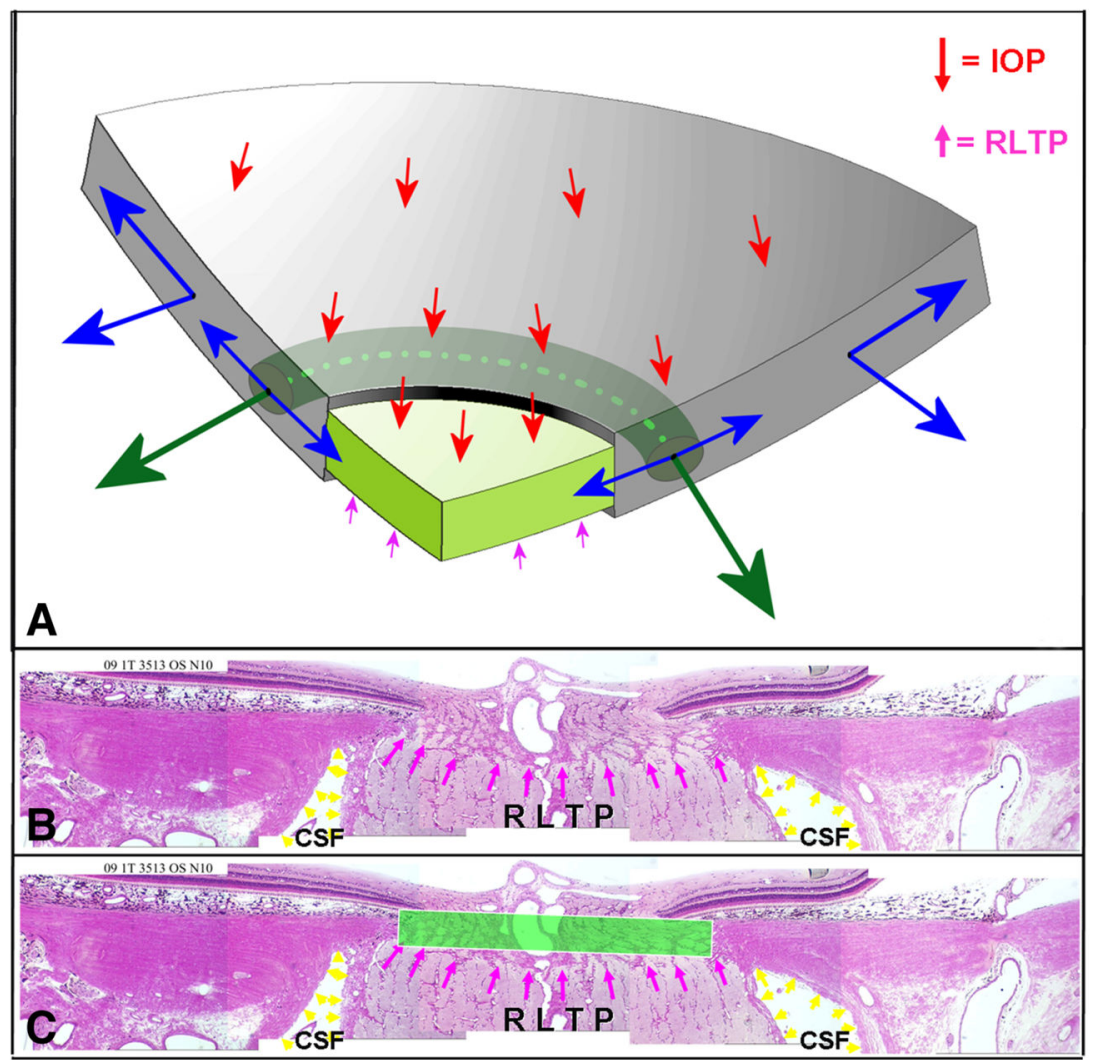

Figure 5. Principle distribution of forces, pressures and the translaminar pressure gradient within the optic nerve head (ONH)

A. Cut-away diagram of IOP-induced mechanical stress in an idealized spherical scleral shell with a circular scleral canal spanned by a more compliant lamina cribrosa. In this case, the majority of the stress generated by IOP/orbital pressure difference (red arrows on the inner surface of the sclera) is transferred into a hoop stress borne within the thickness of the sclera and lamina (blue arrows) that is concentrated circumferentially around the scleral canal (green arrows). B. Note that the pressure behind the lamina is not simply cerebrospinal fluid (CSF) pressure but is retrolaminar tissue pressure (RLTP) which has been demonstrated in dogs to be approximately $0.82 \times \mathrm{CSF}+2.9 \mathrm{~mm} \mathrm{Hg}$ (55). C. The difference between IOP and the retrolaminar tissue pressure is the translaminar pressure difference which generates both a net posterior (outward) force on the surface of the lamina (the red arrows over the lamina) and a hydrostatic pressure gradient (the translaminar pressure gradient - schematically shown in green) within the neural and connective tissues of the prelaminar and laminar regions. Note that the in-plane hoop stress transferred to the lamina from the sclera is much larger than the stresses induced by the translaminar pressure difference. CSF directly influences laminar position through its effect on the translaminar pressure difference. CSF may also effect scleral flange position within the region it projects to the sclera (Fig 2), but in most eyes, because the projection of the CSF space is minimal this is not likely important (the CSF space within Panels B and C in this figure is greatly expanded due to perfusion fixation). IOP has a similar direct effect on laminar position, but has an additional (and potentially more important) effect on laminar position through the peripapillary sclera. However, while the magnitude of the translaminar pressure difference 
may be small relative to the stresses within the sclera and lamina, the axons experience it as the translaminar pressure gradient the steepness of which is influenced by the thickness of the tissues over which it is experienced. The translaminar pressure gradient, as such, may serve as a primary barrier to axon transport and flow within this region and an important physiologic determinant for the $\mathrm{ONH}$ axons and cells. [Reprinted with permission from Experimental Eye Research by International Society for Eye Research, copyright $\odot 2011$ Academic Press (46)]. IOP, intraocular pressure. 


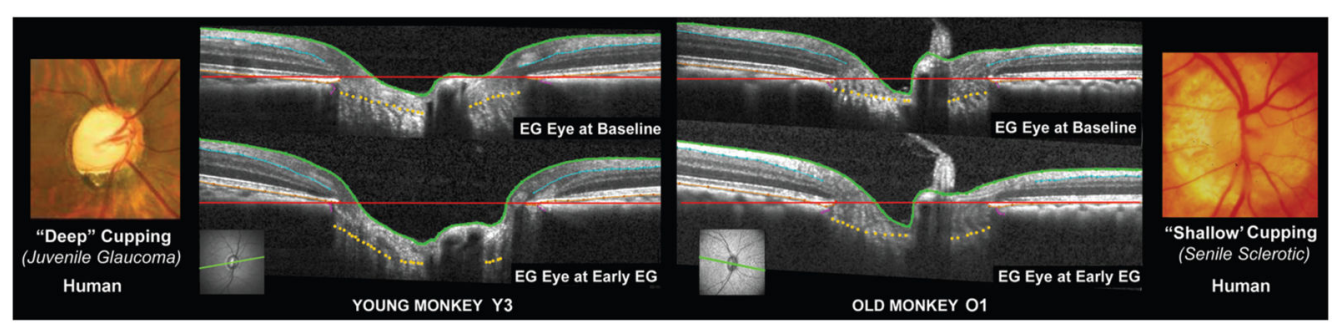

Figure 6. Differences in ONH connective tissue structural stiffness and/or remodeling may underlie "shallow" and "deep" forms of glaucomatous cupping in monkeys and humans Deep (far left) and shallow (far right) forms of human glaucomatous cupping occur at all ages and IOP levels but are classically seen in youthful and elderly eyes, respectively. We have proposed that the ONH connective tissues "harden" with age and that on average aged eyes should demonstrate a shallower form of cupping (i.e. a shallower "phenotype") as a result (37). Spectral domain optical coherence tomography (SDOCT) ONH B-scans (green, lower left) from the EG eye of a young (left) and old (right) monkey, when the eye was normal (upper) and at the second confirmation of confocal scanning laser tomography (CSLT) detection of ONH surface change in the young eye (lower left) and at the (later) presacrifice data set in the old eye (lower right). All images were obtained after 30 minutes of manometer controlled IOP (10 $\mathrm{mm} \mathrm{Hg})$. In both eyes, while prelaminar neural tissue thickness alterations are present, laminar deformation is also apparent as an increase in the magnitude of space between the Bruch's membrane opening reference plane (red line) and the anterior lamina cribrosa surface (gold dots). Laminar deformation in the old eye is far less than in the young eye and this profound difference in laminar deformation occurred in the setting of a cumulative IOP insult that was approximately 5 times greater in the old eye. [Reprinted with permission from Investigative Ophthalmology \& Visual Science, copyright (C) 2014 Association for Research in Vision and Ophthalmology (67)]. ONH, optic nerve head; EG, experimental glaucoma. 

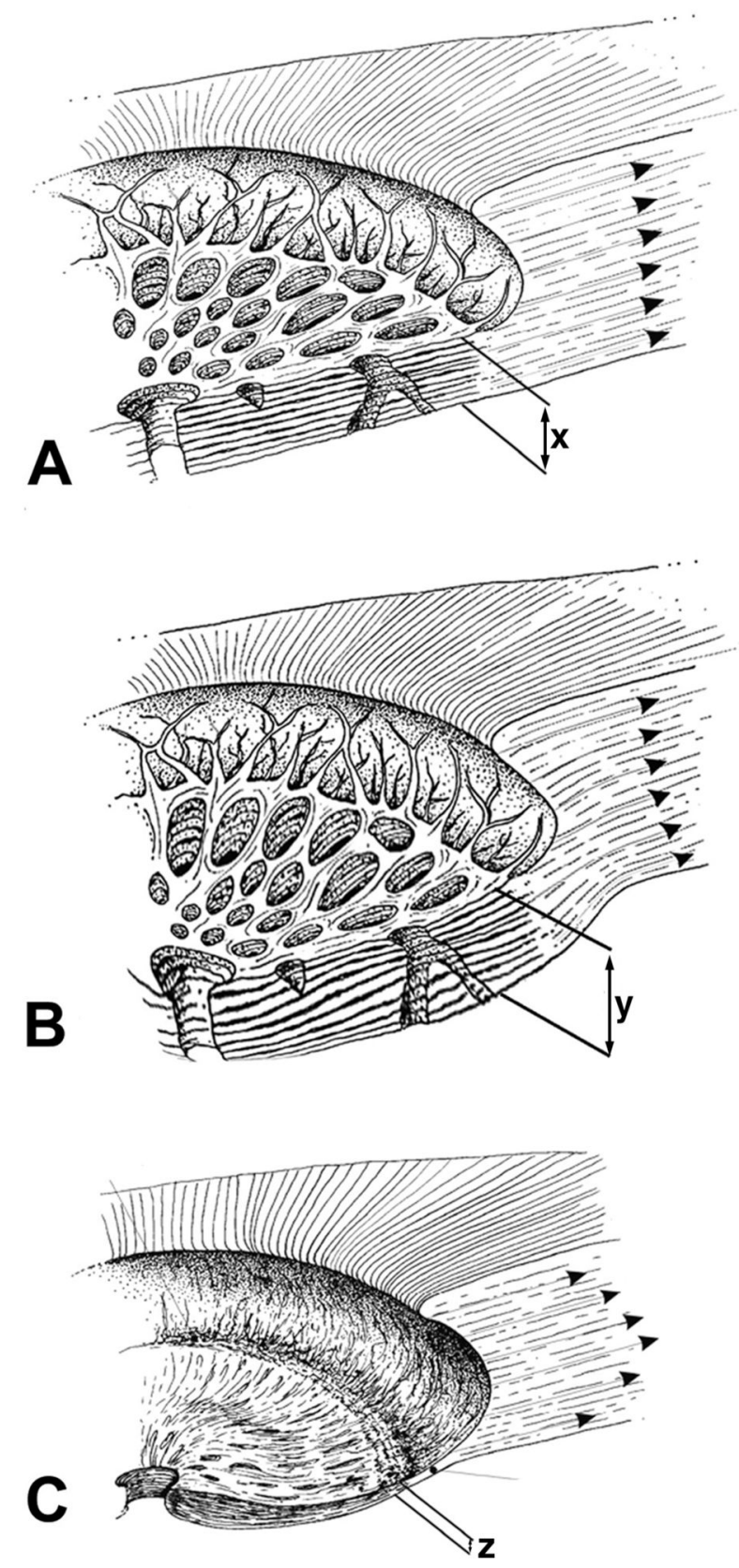

Figure 7. Our Central Hypothesis Regarding ONH Connective Tissue Damage In "Laminar" Cupping

"Deep", "laminar" or "glaucomatous" cupping is a manifestation of ONH connective tissue deformation, remodeling and/or damage which can be caused by either IOP-related or nonIOP-related insults. (See Figure 5). However, regardless of the primary insult to the $\mathrm{ONH}$ connective tissues, their deformation (if present) is driven by IOP-related connective tissue stress and strain. Thus the presence of $\mathrm{ONH}$ connective tissue deformation in any optic neuropathy is evidence that the level of IOP at which it occurred, (whether normal or elevated) is too high for the connective tissues in their present condition. (A) Schematic of normal laminar thickness $(\mathrm{x})$ within the scleral canal with scleral tensile forces acting on the 
scleral canal wall. (B) Early IOP-related damage in the monkey eye (Fig 6) $(18,19,24-27)$ includes posterior bowing of the lamina and peripapillary sclera accompanied by neural canal expansion (mostly within the posterior (outer) scleral portion) and thickening (not thinning) of the lamina (y). In our studies to date this appears to represent mechanical yield (permanent stretching) and or remodeling of the lamina rather than mechanical failure (physical disruption) of the laminar beams. (C) Progression to end-stage damage includes profound scleral canal wall expansion (clinical excavation) and posterior deformation and thinning of the lamina (z) by mechanisms that are as yet uncharacterized. If all other aspects of the neuropathy are identical, the stiffer the lamina, the more resistant it will be to deformation. Whether this is better or worse for the adjacent axons is a separate question that remains to be determined. [Reprinted with permission from Prog Retin Eye Res, copyright $\odot 2005$ Elsevier (45)]. ONH, optic nerve head; IOP, intraocular pressure. 

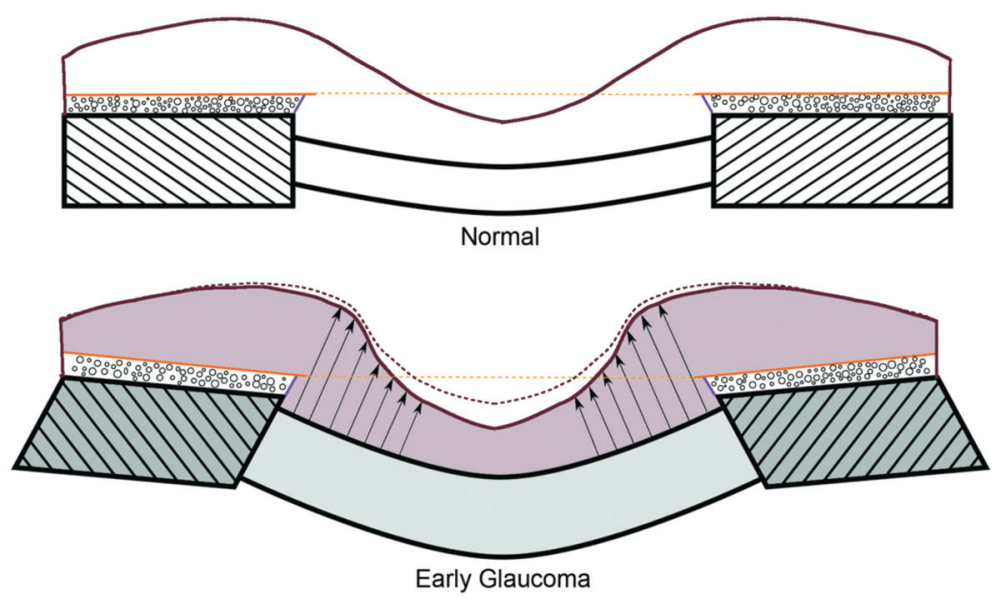

Figure 8. Profound Subsurface Structural Change Accompanies the Onset of CSLT-Detected Clinical Cupping in the Young Adult Monkey Eye but this May be Different in the Old Monkey Eye. Upper

Normal lamina cribrosa (unhatched), scleral flange (hatched), prelaminar tissue (beneath the internal limiting membrane - brown line), Bruch's membrane (solid orange line), Bruch's membrane opening (BMO) zero reference plane (dotted orange line), Border tissue of Elschnig (purple line), choroid (black circles) are schematically represented in the upper illustration. Lower: Overall changes in the ONH surface and subsurface architecture at the onset of CSLT-detected ONH surface change in experimental ocular hypertension in young adult monkey eyes are depicted below. Posterior bowing of the lamina and peripapillary scleral flange, thickening of the lamina and thickening (arrows) not thinning of the prelaminar neural tissues (brown shading) underlie posterior deformation of the $\mathrm{ONH}$ and peripapillary retinal surface (dotted brown to solid brown ILM). Thus, while expansion of the clinical cup and deformation of the surface are clinically detectable at this early stage of the neuropathy, because they occur in the setting of prelaminar tissue thickening, (not thinning), clinical cupping in experimental ocular hypertension in these young adult eyes is "laminar" in origin, without a significant "prelaminar" component (Figure 3). Because aged eyes will have (on average) stiffer connective tissues, we predict they will demonstrate less laminar and more prelaminar cupping at the onset of clinically detectable ONH surface change - a prediction that has been confirmed in a recent study (Fig 6) [Reprinted with permission from Investigative Ophthalmology \& Visual Science, copyright (C) 2007 Association for Research in Vision and Ophthalmology (27)]. ONH, optic nerve head ; CSLT, confocal scanning laser tomography; ILM, internal limiting membrane. 


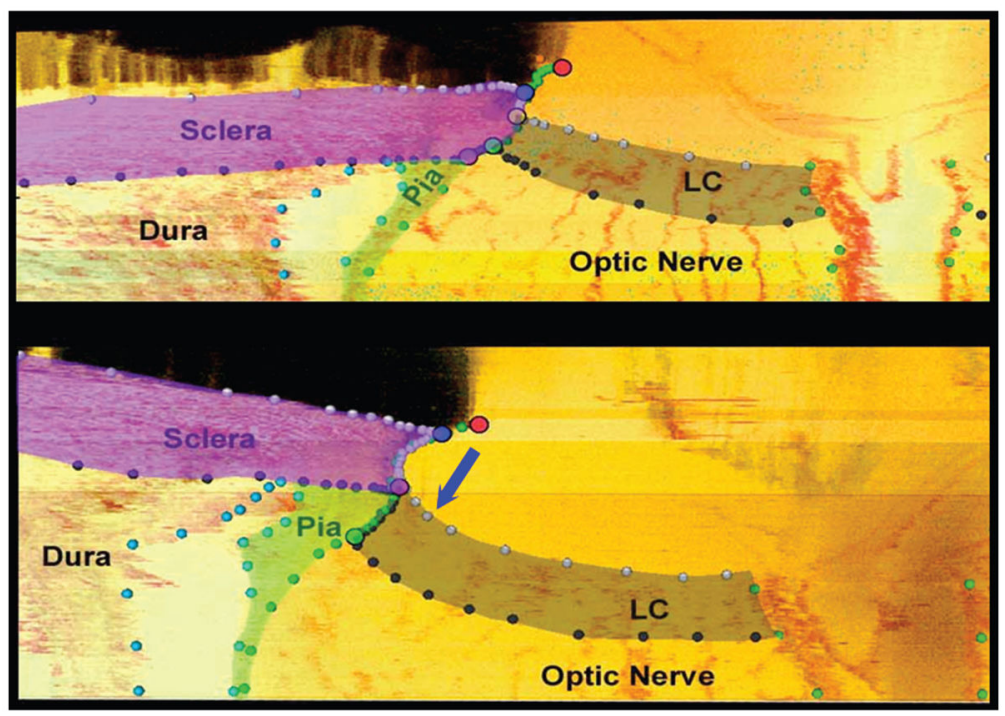

Figure 9. The pathophysiology of early experimental glaucomatous damage to the monkey ONH includes not only "thickening" but regional "migration" of the laminar insertion away from the sclera to the point that "complete pialization" of the laminar insertion is achieved in a subset of eyes (46)

Neural canal landmarks (Red - Neural Canal Opening (end of Bruch's membrane); Blue Anterior Scleral Canal Opening; Yellow - Anterior Laminar Insertion; Green - Posterior Laminar Insertion; Purple - Posterior Scleral Canal Opening) and segmented connective tissue (dark grey - lamina cribrosa; purple - peripapillary sclera; light green - pial sheath) within digital section images from the inferior region of the normal (top) and the contralateral early experimental glaucoma (bottom) ONH of a representative monkey. Note that in most normal monkey eyes, the lamina inserts into the sclera as is demonstrated in this monkey's normal eye (top). However at an identical location in the early experimental glaucoma eye of this animal (bottom) in addition to the lamina being thickened and posteriorly deformed, the laminar insertion has migrated outward such that both the anterior and posterior lamina effectively insert into the pial sheath. While regions of laminar insertion into the pia have been reported in normal human eyes (72) these findings are the first to suggest that active remodeling of the laminar insertion from the sclera into the pia is part of the pathophysiology of "glaucomatous" ONH damage. This phenomenon when present has important implications for the mechanism of axonal insult within these regions. [Reprinted with permission from Experimental Eye Research by International Society for Eye Research, copyright (C) 2011 Academic Press (46)]. ONH, optic nerve head. 

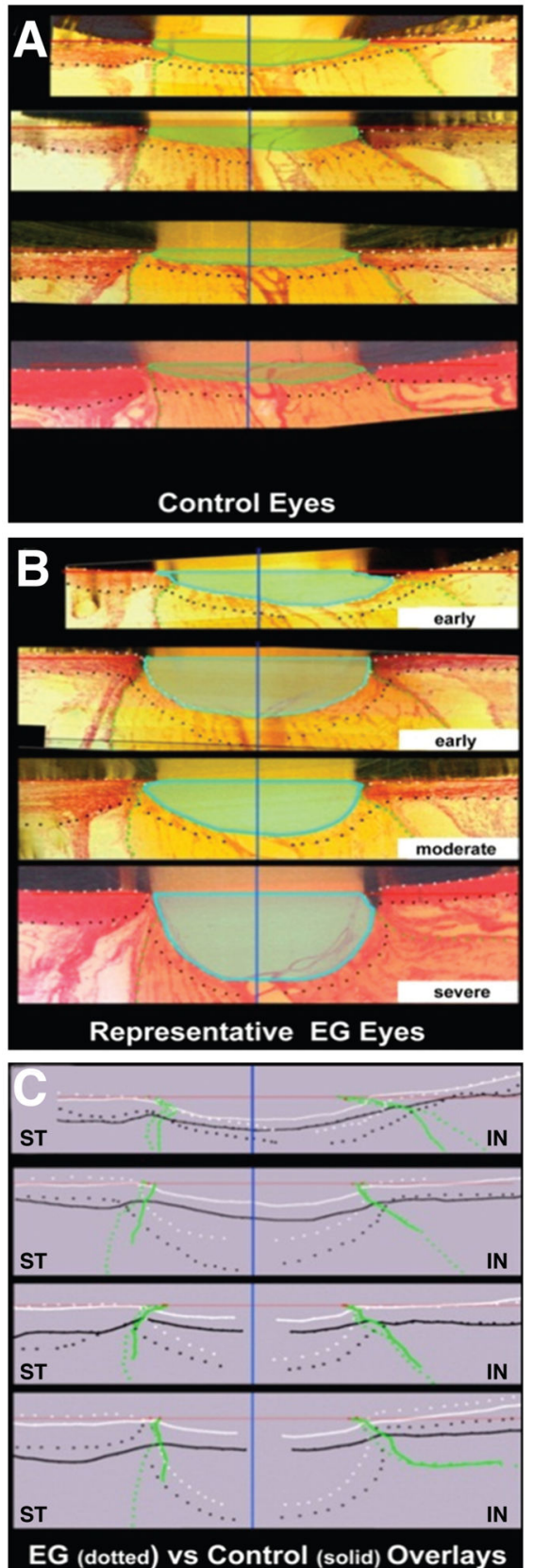

Figure 10. 3D Histomorphometric characterizations of early, moderate and severe monkey EG provide our targets for SDOCT phenotyping of the optic neuropathy of chronic IOP elevation in the monkey and human eye

We have previously proposed that regardless of its contribution to the mechanisms of RGC axonal insult, it is the presence of ONH connective tissue deformation and/or remodeling that underlies and defines a "glaucomatous" form of cupping, and that its character and magnitude determine the cupping "type" (i.e. its glaucoma phenotype) in a given eye. The schematic depiction of central horizontal 3D histomorphometric section images from the Control (A) and EG (B) eyes of 4 representative animals with "early", "moderate" and "severe" axon loss are depicted in $(\mathbf{C})$. Eye-specific, EG eye deformation of the ONH 
connective tissues can be quantified by the (EG - Control eye) difference in our 3D volumetric parameter post-BMO total prelaminar volume (27) (shaded in light green in A and B). ONH connective tissue remodeling includes laminar thickening (also see Figure 5) and thinning and insertion migration (note that the lamina inserts into the pia in the bottom panel of (B) (47). We predict that laminar deformation/remodeling in optic nerve transection will be minimal, making it "non-glaucomatous" in character - a prediction which is in the process of being confirmed in 5 unilateral optic nerve transection (ONT) animals (73), EG, experimental glaucoma; RGC, retinal ganglion cell; IOP, intraocular pressure; $\mathrm{ONH}$, optic nerve head. 

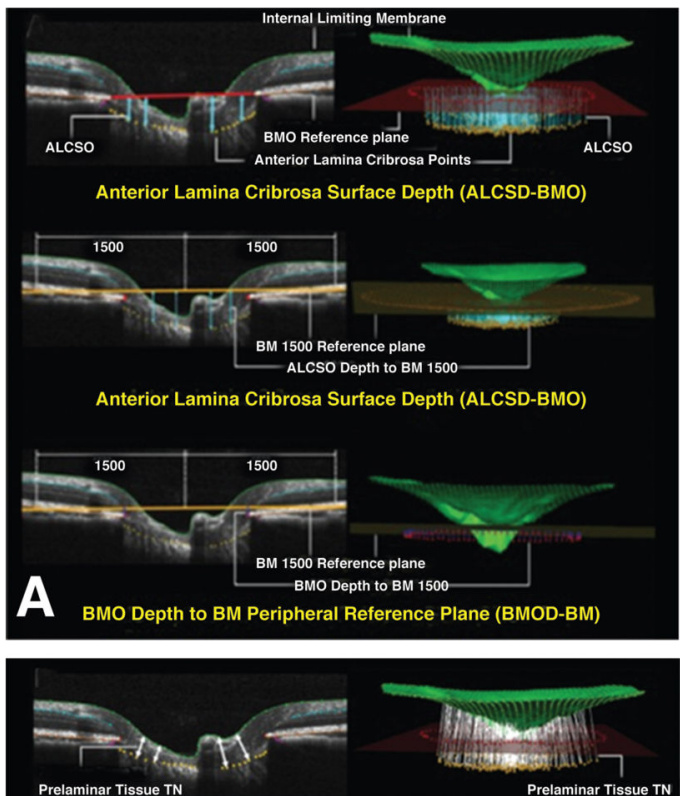

Prelaminar Tissue Thickness (PLTT)
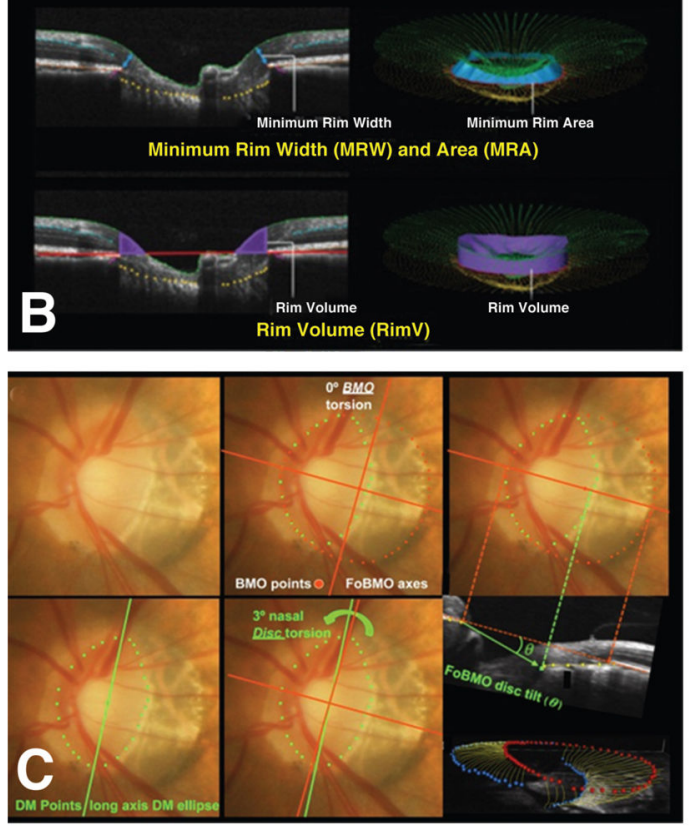

Figure 11. SDOCT ONH, RNFL and Macular data sets acquired relative to the SDOCT determined Foveal to BMO (FoBMO) axis

FoBMO ONH $768 \times 256$ grid, 48 radial, RNFL Circle and macula Grid scans identically acquired using eye tracking ( 82 ) each time the eye is imaged after BMO, its center and the fovea are anatomically identified during the first imaging session. $\mathrm{ONH}$, optic nerve head; RNFL, retinal nerve fiber layer; BMO, Bruch's membrane opening; FOBMO, foveal-BMO centroid. 


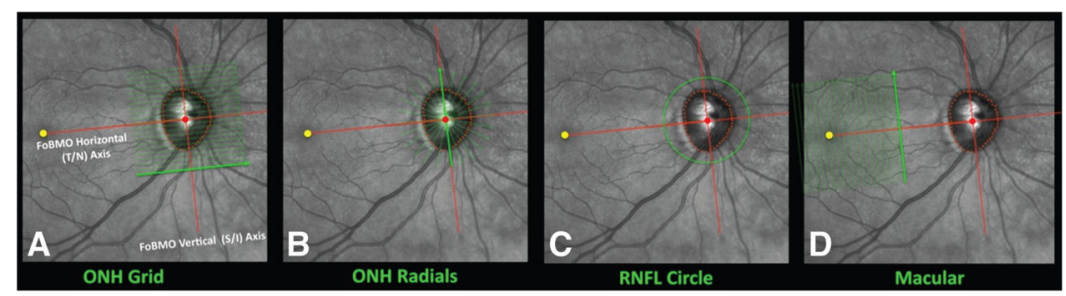

Figure 12. FoBMO ONH phenotyping will include quantification of ONH tilt, torsion and the neural canal minimum

We have published extensively on the ONH parameters ALCSD-BMO, ALCSD-BM, BMOD-BM, PLTT, MRW, MRA and Rim Volume [(A) and (B) $(69,81,83-85)]$. The SDOCT definitions of ONH torsion and tilt are evolving $(86,87)$. ONH torsion will be defined as the angle of the long axis of the disc margin ellipse relative to the vertical FoBMO axis ((C) - lower center). BMO torsion will be defined as the angle of the long axis of the BMO ellipse relative to the FoBMO vertical axis (shown as zero in (C - upper middle) because $\mathrm{BMO}$ is a circle). $\mathrm{ONH}$ tilt will be defined as the angle between a line connecting the nasal BMO point and the temporal SDOCT projection of the Disc Margin within the FoBMO B-scan (C - lower right). The neural canal minimum defines the smallest crosssectional area through which the RGC axons pass using all BMO (red) and anterior scleral canal opening (blue) points (lower right) $(81,88)$.

ALCSD, Anterior lamina cribrosa surface depth; ALCSD-BM, Anterior lamina cribrosa surface depth relative to BM reference plane; BM, Bruch's membrane; BMO, Bruch's Membrane opening; BMOD-BM, Bruch's membrane opening depth relative to BM reference plane; FoBMO, Foveal-BMO $\mathrm{B}_{\text {centroid }}$;RA, Minimum rim area; MRW, Minimum rim width; ONH, Optic Nerve Head; PLTT, Prelaminar tissue thickness; RGC, Retinal ganglion cell; RimV, Rim volume; SDOCT, Spectral domain optical coherence tomography. 